\title{
HAFTANIN GÜNÜ ETKİSI: BIST 30 ENDEKSİ PAYLARI ÜZERİNE BİR ARAŞTIRMA
}

\author{
Murat AKBALIK* \\ Nasıf ÖZKAN*
}

\section{Öz}

Bu çalışmada, Ağustos 2015 tarihi itibarıyla BIST 30 endeksinde yer alan paylarda haftanın günü etkisi, Türkiye'de yaşanan 2001 krizi sonrası dönemi için bu endekste yer alan payların Ocak 2003-Mayıs 2015 tarihleri arasındaki getiri verileri kullanılarak araştırılmaktadır. Literatürde yapılan çalışmaların çoğundan farklı olarak, bu etki bir endeks yerine bir endeks içinde (BIST 30) yer alan bireysel paylar için yapılmaktadır. $\mathrm{Bu}$ etkiyi analiz etmek içinse, parametrik olmayan istatistiksel analiz yöntemlerinden olan Kruskal-Wallis testi ve Wilcoxon sıralama toplamı testi uygulanmaktadır. Çalışmanın sonuçları, BIMAS, EKGYO ve TCELL payları dışındaki tüm paylarda haftanın günü etkisinin varlığına ilişkin kanıtlar sunamamaktadır. BIMAS ve TCELL için cuma günü getirisi; EKGYO içinse, pazartesi günü getirisi haftanın diğer günlerinin getirilerine göre daha yüksektir.

Anahtar Kelimeler: Piyasa Etkinliği, Mevsimsel Anomaliler, Gün Etkisi, Borsa İstanbul 30 Endeksi Jel Kodları: G02, G11, G12, G14

\section{THE DAY OF THE WEEK EFFECT: A STUDY ON THE STOCKS OF BIST 30 INDEX}

\footnotetext{
Abstract

This study aims to analyze the day of the week effect in BIST 30 Index by August 2015. In this respect, the stock market data, which consist of BIST 30 stock returns, were used from January 2003 to May 2015. Contrary to most studies in the relevant literature, individual stocks are considered for the above-mentioned analysis. In order to analyze this effect, we have applied nonparametric statistical analysis methods, which

* Doç. Dr. Murat Akbalık, Marmara Üniversitesi, Bankacılık ve Sigortacılık Yüksekokulu, Sermaye Piyasası Bölümü, e-posta: makbalik@marmara.edu.tr

** Arş. Gör. Dr., Dumlupınar Üniversitesi Uygulamalı Bilimler Yüksekokulu Bankacılık ve Finans Bölümü, e-posta: nasif.ozkan@dpu.edu.tr
} 
are the Kruskal-Wallis test and the Wilcoxon rank sum test. The results of the paper cannot provide evidence of the presence of the day of the week effects on all the stocks, but apply particularly to BIMAS, EKGYO, and TCELL. The return of Friday for BIMAS and TCELL and the return of Monday for EKGYO are higher than the return on other days of the week.

Keywords: Efficiency, Seasonal Anomalies, Day Effect, Borsa Istanbul 30 Index Jel Codes: G02, G11, G12, G14

\section{Giriş}

Payların belirli gün, hafta ve aylardaki getirilerini inceleyen birçok ampirik çalışma, payların bazı günlerde, haftalarda ve aylarda daha yüksek ya da daha düşük getiri sağladığını göstermektedir. Bu bulgular, piyasada pay fiyatlarının pay ile ilgili tüm bilgileri yansıttığını ve bu nedenle de hiçbir yatırımcının ortalamanın üzerinde bir getiri elde edemeyeceğini ileri süren etkin piyasalar hipotezi (Fama, 1965, 34-105; Samuelson, 1965, 41-49; Fama, 1970, 383-417) ile çelişmektedir. Etkin piyasalar hipotezine aykırı olan bu bulgular, literatürde mevsimsel ya da takvimsel anomaliler olarak tanımlanmaktadır.

$\mathrm{Bu}$ çalışmada, mevsimsel anomalilerden haftanın günlerine ilişkin anomali ya da literatürde yaygın olarak bilinen adıyla haftanın günü etkisi (the day off the week effect) anomalisi Borsa İstanbul için incelenmektedir. Haftanın günü etkisinin geçerli olduğu piyasalarda payların ortalama getirileri haftanın günlerine göre istatistiksel olarak anlamlı bir şekilde farklılaşabilmektedir. Çalışmada, Borsa İstanbul pay piyasasında haftanın günü etkisini araştırmak için, 20 Ağustos 2015 tarihi itibarıyla Borsa İstanbul 30 endeksinde (BIST 30) yer alan otuz payın 02.01.2003-29.05.2015 tarihleri arasındaki verileri kullanılmaktadır. Haftanın günlerine (pazartesi, salı, çarşamba, perşembe ve cuma) ilişkin ortalama getirilerin birbirinden farklı olup olmadığını belirlemek içinse, parametrik olmayan istatistiksel analiz yöntemlerinden olan Kruskal-Wallis testi ve Wilcoxon sıralama toplamı testi uygulanmaktadır. Literatürde yapılan ulusal ve uluslararası birçok çalışmanın (Jaffe ve Westerfield, 1985, 434; Karan ve Uygur, 2001, 106; Hui, 2005, 278; Ergül, Akel ve Dumanoğlu, 2009, 137; Büyükşalvarci, 2010, 111) haftanın günü etkisini araştırmak için veri olarak pay endekslerini ya da portföylerini (S\&P 500 Index, Nikkei 225 Index, Hang Seng Index, BIST100 Endeksi ve BIST Sektör Endeksleri gibi) kullandıkları göze çarpmaktadır. Bu nedenle Borsa İstanbul pay piyasasında işlem gören piyasa değeri en yüksek otuz şirket ya da başka bir ifadeyle BIST 30 endeksi içinde yer alan 30 adet bireysel pay üzerinde haftanın günü etkisinin araştırılıyor olması çalışmayı diğerlerinden ayırmaktadır.

Çalışma beş bölümden oluşmaktadır. Giriş bölümünü takip eden ikinci bölümde haftanın günü etkisini, ulusal ve uluslararası piyasalarda inceleyen literatür çalışmalarına yer verilmektedir. Üçüncü bölümde, çalışmada kullanılan veri seti ve metodoloji açıklanmaktadır. Dördüncü bölümde, BIST 30 payları için haftanın günü etkisine dair elde edilen bulgular yorumlanmaktadır. Son bölümde ise, çalışmanın sonuçları özetlenmektedir. 


\section{Literatür Taraması}

Mevsimsel anomalilerden olan haftanın günü etkisi, finans literatüründe yaygın olarak araştırılan konulardan birisidir. Bu konuyla ilgili ilk çalışmalar, Amerika Birleşik Devletleri (ABD) pay piyasasında gerçekleştirilmiş ve bu çalışmalarda payların pazartesi günü ortalama getirilerinin diğer hafta içi günlere göre daha düşük ve negatif olduğu gösterilmiştir (Cross, 1973, 67-69; French, 1980, 55-69; Gibbons ve Hess, 1981, 579-596; Keim ve Stambaugh, 1984, 819835; Smirlock ve Starks, 1986, 197-210). Ayrıca Avusturalya, Japonya, Asya ve Avrupa ülkelerini içine alan diğer uluslararası çalışmalarda da benzer sonuçlar ortaya koyulmaktadır (Jaffe ve Westerfield, 1985, 433-454; Condoyanni, O’Hanlon ve Ward, 1987, 159-174; Chang, Pinegar ve Ravichandran, 1993, 497-513; Choudhry, 2000, 235-242). Diğer taraftan literatürde, haftanın günü etkisinin farklı günlerde gerçekleştiğini ileri süren çalışmalarda bulunmaktadır. Brooks ve Persand (2001), Malezya ve Tayland'da; Jaffe ve Westerfield (1985) ile Dubois ve Louvet (1996) da Avusturalya ve Japonyada; Solnik ve Bousquet (1990) ise, Fransa'da payların ortalama getirilerinin salı günü diğer günlere göre daha düşük ve negatif olma eğiliminde olduğunu göstermektedir.

Son yıllarda yapılan uluslararası çalışmalar, gelişmiş ve gelişmekte olan piyasalarda haftanın günü etkisin azaldığını ya da yok olduğunu belirtmektedir (Rubinstein, 2001, 25; Steeley, 2001, 1941; Kamath ve Chusanachoti, 2002, 47; Ajayi, Mehdian ve Perry, 2004, 53; Kohers, Kohers, Pandey ve Kohers, 2004, 167; Hui, 2005, 277 ; Liu ve Li, 2010, 78). Connolly (1989, 1991), Chang vd. (1993) ve Easton ve Faff (1994) örneklem büyüklüğü ve/veya hata terimi düzenlemelerinin; Gregoriou, Kontonikas ve Tsitsianis (2004) işlem maliyetlerinin haftanın günü etkisini anlamsız hale getirdiğini ileri sürmektedir. Sullivan, Timmermann ve White (2001) ise, haftanın günü etkisinin veri madenciliğinin bir sonucu olabileceğini iddia etmektedir. Basher ve Sadorsky (2006) inceledikleri 21 gelişmekte olan ülke piyasasının çoğunda haftanın günü etkisinin var olmadığını ancak bazı ülkelerde bu etkinin varlığını hala güçlü bir şekilde koruduğunu ortaya koymaktadır. Diğer taraftan Dicle ve Levendis (2014), 33 ülkede 51 uluslararası piyasayı inceledikleri çalışmalarında, haftanın günü etkisinin analize dahil edilen piyasaların çoğunda devam ettiğini göstermektedir. Tüm bu çalışmalar, uluslararası piyasalarda haftanın günü etkisinin varlığına yönelik farklı kanıtlar sunmakta ve kullandıkları gelişmiş istatistiksel yöntemlerle bu etkinin varlığı ile ilgili şüpheli sonuçlar bildirmektedir. 
Tablo I. Türkiye'de Haftanın Günü Etkisi Üzerine Yapılan Çalışmalar

\begin{tabular}{|ccl|}
\hline Çalışma & Dönem & \multicolumn{1}{c|}{ Sonuç } \\
\hline Muradoğlu ve Oktay (1993) & $1988-1992$ & $\begin{array}{l}\text { Salı günü getirileri negatif, cuma günü getirileri } \\
\text { pozitiftir. }\end{array}$ \\
\hline Balaban (1995) & $1988-1994$ & $\begin{array}{l}\text { Salı, istatistiksel olarak anlamsız bir şekilde haftanın } \\
\text { en düşük getirisinin; cuma ise, en yüksek getirisinin } \\
\text { sağlandığ1 gündür. }\end{array}$ \\
\hline
\end{tabular}

Özmen (1997)

1988-1996

Salı, istatistiksel olarak anlamsız bir şekilde negatif getirinin; cuma ise, pozitif ve en yüksek getirinin sağlandığı gündür. Ayrıca çarşamba, en yüksek ikinci getiriyi sağlayan gündür.

Bildik (2000)

1988-1999

$1991-1998$

1997-2001

1988-1996

1988-1999

Oğuzsoy ve Güven (2003)

İnamlık, Berument ve Kıymaz (2004)

1986-2003

$1988-2003$

Tunçel (2007)

2002-2005

Dicle ve Hassan (2007)

1987-2005

Aktaş ve Kozanoğlu (2007)

2001-2007
Salı günü getirileri negatif, cuma günü getirileri pozitiftir.

Pazartesi ve salı istatistiksel olarak anlamsız bir şekilde haftanın en düşük getirisinin sağlandığ 1 günlerdir. Cuma, en yüksek getirinin sağlandığ 1 gündür.

Cuma, en yüksek getirinin sağlandığı gündür.

Cuma günü getirileri pozitiftir.

Salı en düşük getirinin; cuma ise, en yüksek getirinin sağlandığ gündür.

Pazartesi en düşük getirinin; cuma ise, en yüksek getirinin sağlandığı gündür.

Pazartesi en düşük getirinin sağlandığı günken, perşembe ve cuma en yüksek getirinin sağlandığ günlerdir.

Pazartesi en düşük getirinin; cuma ise, en yüksek getirinin sağlandığı gündür.

Pazartesi günü getirileri negatif, perşembe ve cuma günü getirileri pozitiftir.

Perşembe ve cuma günü getirileri istatistiksel olarak anlamlıdır. 


\begin{tabular}{|c|c|c|}
\hline Atakan (2008) & $1987-2008$ & $\begin{array}{l}\text { Pazartesi en düşük getirinin; cuma ise, en yüksek } \\
\text { getirinin sağlandığı gündür. }\end{array}$ \\
\hline Tuncel (2008) & $2005-2007$ & Haftanın günü etkisi yoktur. \\
\hline $\begin{array}{l}\text { Ergül, Dumanoğlu ve Akel } \\
\qquad(2008)\end{array}$ & $1988-2007$ & $\begin{array}{l}\text { Tüm dönem için haftanın günü etkisi yokken, bazı } \\
\text { yıllarda haftanın günü etkisi tespit edilmiştir. }\end{array}$ \\
\hline Hamarat ve Tufan (2008) & $1997-2005$ & $\begin{array}{l}\text { Pazartesi en düşük getirinin; perşembe ise, en } \\
\text { yüksek getirinin sağlandığı gündür. }\end{array}$ \\
\hline Ergül vd. (2009) & $2000-2007$ & $\begin{array}{l}\text { Çarşamba ve perşembe en düşük getirinin } \\
\text { sağlandığı günlerken, cuma en yüksek getirinin } \\
\text { sağlandığı gündür. }\end{array}$ \\
\hline $\begin{array}{l}\text { Korkmaz, Başaran ve Çevik } \\
\text { (2010) }\end{array}$ & $1987-2009$ & Pazartesi en düşük getirinin sağlandığı gündür. \\
\hline Eken ve Uner (2010) & 1988-2007 & Haftanın günü etkisi vardır. \\
\hline Güneysu ve Yamak (2011) & $1990-201$ & Haftanın günü etkisi vardır. \\
\hline Başdaş (2011) & $1988-2010$ & Haftanın günü etkisi sınırlıdır. \\
\hline $\begin{array}{l}\text { Abdioğlu ve Değirmenci } \\
\qquad(2013)\end{array}$ & 2003-2012 & $\begin{array}{l}2008 \text { krizi öncesinde pazartesi en düşük getirinin; } \\
\text { cuma ise, en yüksek getirinin sağlandığı gündür. }\end{array}$ \\
\hline Çiçek (2013) & $2008-2012$ & Pazartesi en yüksek getirinin sağlandığı gündür. \\
\hline Konak ve Kendirli (2014) & 2005-2012 & Cuma en yüksek getirinin sağlandığı gündür. \\
\hline
\end{tabular}

Türkiye pay piyasasında da haftanın günü etkisinin ayrıntılı bir şekilde araştırıldı̆̆ı görülmektedir. Konuyla ilgili araştırmalar, bu araştırmaların uygulandığı dönem ve araştırmaların sonuçları Tablo 1'de sunulmaktadır. Tablo 1'den de görülebileceği gibi birçok çalışma, Borsa İstanbul pay piyasasında haftanın günü etkisinin varlığını ortaya koyan bulgular sunmaktadır. Bu çalışmaların sonuçları genel olarak değerlendirildiğinde, Borsa İstanbul pay piyasasında pazartesi ve salı haftanın en düşük getiri sağlayan günleri; cuma ise, haftanın en yüksek getiri sağlayan günüdür. Türkiye’de Borsa İstanbul pay piyasası dışındaki altın piyasası (Aksoy, 2013, 149-164), vadeli işlemler ve opsiyon piyasası (Kayalıdere ve Aktaş, 2012, 321-338) devlet iç borçlanma senetleri piyasası (Çiçek, 2008, 93-118) ve döviz piyasasında (Aydoğan ve Geoffrey Booth, 2003, 353-360) da haftanın günü etkisi araştırılmaktadır. 


\section{Veri Seti ve Metodoloji}

Bu çalışmada, 20 Ağustos 2015 tarihi itibariyle BIST 30 endeksinde $^{1}$ yer alan otuz payın 02.01.2003-29.05.2015 dönemine ait günlük kapanış fiyatları kullanılmaktadır. Veriler, Finnet Hisse Expert programından elde edilmiştir. Tablo 2'de analize dahil edilen şirketlerin faaliyet gösterdiği sektörler, analiz edilen gün sayıları ve analize başlangıç tarihleri sunulmaktadır. Tablo 2'de görüldüğü gibi örnekleme dahil edilen şirketlerin 14'ü mali kuruluşlar $(\% 46,6)$, 8’i imalat sanayi $(\% 26,6)$, 4’ü ulaştırma, haberleşme ve depolama (\%13,3), 2'si toptan ve perakende ticaret, otel ve lokantalar $(\% 6,6)$, 1'i inşaat $(\% 3,3)$ ve 1'i de madencilik $(\% 3,3)$ sektöründe faaliyet göstermektedir. Bazı paylar, 2003 yılından sonra Borsa İstanbul'da işlem görmeye başlamıştır. Bu nedenle bu paylar için analize başlangıç tarihi 02.01.2003’ten farklıdır. Örneğin BIMAS için analize başlama tarihi, bu payın borsada ilk işlem görmeye başladığ 1 tarih olan 15.07.2005’tir. Tablo 2'de gösterildiği gibi, yirmi bir pay için analize başlangıç tarihi 02.01.2003'tür.

Tablo 2. BIST 30 Paylarına ve Analize İlişkin Bilgiler

\begin{tabular}{llcc}
\hline Pay Kodu & Sektör & $\begin{array}{c}\text { Analiz Edilen } \\
\text { Gün Sayısı }\end{array}$ & $\begin{array}{c}\text { Analize Başlangıç } \\
\text { Tarihi }\end{array}$ \\
\hline AKBNK & Mali & 3113 & 02.01 .2003 \\
ARCLK & İmalat & 3113 & 02.01 .2003 \\
BIMAS & Toptan Per. & 2482 & 15.07 .2005 \\
DOHOL & Mali & 3113 & 02.01 .2003 \\
EKGYO & Mali & 1131 & 02.12 .2010 \\
ENKAI & İşaat & 3113 & 02.01 .2003 \\
EREGL & İmalat & 3113 & 02.01 .2003 \\
FROTO & İmalat & 3113 & 02.01 .2003 \\
GARAN & Mali & 3113 & 02.01 .2003 \\
HALKB & Mali & 2025 & 10.05 .2007 \\
ISCTR & Mali & 3113 & 02.01 .2003 \\
KCHOL & Mali & 3113 & 02.01 .2003 \\
KOZAL & Madencilik & 1330 & 12.02 .2010 \\
KRDMD & Mali & 3113 & 02.01 .2003 \\
MGROS & Toptan Per. & 3113 & 02.01 .2003 \\
OTKAR & İmalat & 3113 & 02.01 .2003 \\
PETKM & İmalat & 3113 & 02.01 .2003 \\
PGSUS & Ulaştırma & 522 & 26.04 .2013 \\
SAHOL & Mali & 3113 & 02.01 .2003 \\
SISE & Mali & 3113 & 02.01 .2003 \\
TAVHL & Mali & 2078 & 23.02 .2007 \\
TCELL & Ulaştırma & 3113 & 02.01 .2003 \\
THYAO & Ulaştırma & 3113 & 02.01 .2003 \\
TKFEN & Mali & 1887 & 23.11 .2007 \\
TOASO & İmalat & 3113 & 02.01 .2003 \\
TTKOM & Ulaştırma & 1767 & 15.05 .2008 \\
TUPRS & İmalat & 3113 & 02.01 .2003 \\
ULKER & İmalat & 3113 & 02.01 .2003 \\
VAKBN & Mali & 2395 & 18.11 .2005 \\
YKBNK & Mali & 3113 & 02.01 .2003 \\
\hline & & & \\
\hline & & & \\
\hline
\end{tabular}

1 Bu endeks, Ulusal Pazar’da işlem gören şirketlerle, Kurumsal Ürünler Pazarı’nda işlem gören gayrimenkul yatırım ortaklıkları ve girişim sermayesi yatıım ortaklıkları arasından seçilen otuz paydan oluşmaktadır. 
Paylara ilişkin günlük getiriler aşağıdaki formül yardımıyla hesaplanmaktadır:

$$
\mathrm{R}_{\mathrm{i}, \mathrm{t}}=\ln \left(\frac{\mathrm{P}_{\mathrm{i}, \mathrm{t}}}{\mathrm{P}_{\mathrm{i}, \mathrm{t}-1}}\right)
$$

Denklem (1)'deki $\mathrm{R}_{\mathrm{i}, \mathrm{t}}$; i payının t günündeki logaritmik getirisini, $\mathrm{P}_{\mathrm{i}, \mathrm{t}}$; i payının $\mathrm{t}$ günündeki kapanış fiyatını, $\mathrm{P}_{\mathrm{i}, \mathrm{t}-1}$ ise; i payının t-1 günündeki kapanış fiyatını temsil etmektedir. Getirilerin doğal logaritmalarının (ln) alınarak hesaplanmasının nedeni, veri setinde yer alan uç değerlerin sonuçlar üzerinde yaratacağı olumsuz etkilerin ortadan kaldırılmak istenmesidir (Tunçel, 2007, 259; Ergül vd., 2008, 606; Ergül vd., 2009, 138).

Literatürde yapılan çalışmalar, haftanın günleri etkisini araştırmak için kukla değişkenli regresyon analizleri (Karan ve Uygur, 2001, 108; Abdioğlu ve Değirmenci, 2013, 62-63), GARCH modelleri (Aktaş ve Kozanoğlu, 2007, 40; Atakan, 2008, 103-108), parametrik istatistiksel analiz yöntemleri (Ergül vd., 2008, 606; Büyükşalvarci, 2010, 111-114) veya parametrik olmayan istatistiksel analiz yöntemlerini (Hui, 2005, 279; Tunçel, 2007, 260) kullanmaktadır. Bu çalışmada, öncelikle verilerin normal dağılıma uyup uymadığ 1 Kolmogorov-Smirnov testiyle (KS) araştırılmaktadır. Bu testin sonuçlarına göre, pay getirilerinin normal dağılım özelliklerine uymadıkları tespit edilmiştir (Tablo 4). Bu nedenle de parametrik olmayan istatistiksel analiz yöntemlerinden olan Kruskal-Wallis testine (KW) başvurulmakta ve haftanın günlerine ilişkin ortalama getirilerin birbirinden farklı olup olmadığını belirlemek için bu test SPSS 15.0 istatistik paket programı kullanılarak uygulanmaktadır. Kruskal-Wallis testi (diğer adıyla Kruskal-Wallis $\mathrm{H}$ testi), tek yönlü varyans analizinin (one-way ANOVA) parametrik olmayan alternatifi olarak bilinmektedir. Bu test, sürekli değişkenlere sahip üç ya da daha fazla grup için karşılaştırma yapmayı sağlamaktadır (Kalayc1, 2010, 106). Kruskal-Wallis testinde, KW değeri (ki-kare istatistiği) aşağıdaki formülle hesaplanmaktadır (Hui, 2005, 279; Lim ve Chia, 2010, 2).

$$
K W=\frac{12}{n(n+1)} \sum_{i=1}^{k} \frac{R_{i}^{2}}{n_{i}}-3(n+1)
$$

Denklem (2)'de k işlem günü sayısını $(\mathrm{k}=5)$, n getirilerin toplam gözlem sayısını, $\mathrm{n}_{\mathrm{i}} \mathrm{i}$ işlem günündeki getirilerin gözlem sayısını ve $R_{i}$ ise, $i$ işlem günündeki sıralama sayılarının toplamını göstermektedir.

Çalışmada, haftanın günü etkisinin varlığını test etmek için oluşturulan hipotezler aşağıdaki gibidir.

$\mathrm{H}_{0}$ : Payların hafta içi günlerde sağladığ

$\mathrm{H}_{1}$ : Payların hafta içi günlerde sağladığı ortalama getiriler arasında farklılık vardır.

Kruskal-Wallis testi sonucunda, $\mathrm{H}_{0}$ hipotezinin reddedilmesi haftanın günü etkisinin var olduğu 
anlamına gelmektedir. Bir başka ifadeyle böyle bir sonuç, payların hafta içi günlerde sağladığı ortalama getiriler arasında farklllık olduğunu işaret etmektedir. Hafta içi günlerden hangi ikisinin ortalama getirileri arasında anlamlı farklılık olduğunu belirlemek içinse, Wilcoxon sıralama toplamı testi (Wilcoxon rank sum test) kullanılmaktadır. Wilcoxon sıralama toplamı testinde $\mathrm{Z}$ istatistiği değerine aşağıdaki formülle ulaşılmaktadır (Hui, 2005, 279; Lim ve Chia, 2010, 3):

$$
\begin{gathered}
\mathrm{Z}=\frac{\mathrm{T}-\mu_{\mathrm{T}}}{\sigma_{\mathrm{T}}^{2}} \\
\mathrm{E}(\mathrm{T})=\mu_{\mathrm{T}}=\frac{\mathrm{n}_{1}\left(\mathrm{n}_{1}+\mathrm{n}_{2}+1\right)}{2} \\
\operatorname{Var}(\mathrm{T})=\sigma_{\mathrm{T}}^{2}=\frac{\mathrm{n}_{1} \mathrm{n}_{2}\left(\mathrm{n}_{1}+\mathrm{n}_{2}+1\right)}{12}
\end{gathered}
$$

Denklem (3)'te yer alan $\mu_{\mathrm{T}}$ Wilcoxon siralama toplamı testi ortalamasını; $\sigma_{\mathrm{T}}{ }^{2}$ ise, Wilcoxon sıralama toplamı testi varyansını ifade etmektedir. Denklem (4) ve (5), Wilcoxon sıralama toplamı testine ilişkin ortalama ve varyansın nasıl hesaplandığını göstermektedir. Denklemlerde yer alan $\mathrm{n}_{1}$, birinci örneklemdeki gözlem sayısını; $\mathrm{n}_{2}$ ise, ikinci örneklemedeki gözlem sayısını temsil etmektedir. $\mathrm{T}$ ise, birinci örnekleme $\left(\mathrm{n}_{1}\right)$ ilişkin gözlemlerin sıra toplamıdır.

\section{Ampirik Bulgular}

BIST 30 endeksinde yer alan otuz payın haftanın her bir gününe (pazartesi, salı, çarşamba, perşembe ve cuma) ilişkin ortalama getiri (Ort.) ve standart sapma (Std.) değerleri Tablo 3'de sunulmaktadır. Pazartesi günü, sadece üç pay (DOHOL, TCELL ve YKBNK) negatif ortalama getiri sağlamaktadır. Ancak, bu getiriler istatistiksel olarak anlamsız bir başka ifadeyle sıfırdan farksızdır. Diğer taraftan, pazartesi günü dört pay (EKGYO, PGSUS, THYAO ve ULKER) istatistiksel olarak anlamlı pozitif ortalama getiri sağlamaktadır. Bu bulgu, pazartesi gününün haftanın diğer dört gününden daha düşük getiri sağladığını ileri süren gelişmiş piyasa çalışmalarının bulguları ile çelişmektedir (French, 1980, 55-69; Gibbons ve Hess, 1981, 579-596).

Borsa İstanbul üzerine yapılan bazı çalışmalar, piyasada salı gününe ait getirilerin negatif olduğunu göstermektedir (Muradoğlu ve Oktay, 1993, 51-62; Bildik, 2000; Oğuzsoy ve Güven, 2003, 959-971). Ancak Tablo 3'den, salı günü hiçbir payın istatistiksel olarak anlamlı negatif ortalama getiriye sahip olmadığı görülmektedir. Aksine, salı günü pay (EREGL, FROTO ve ULKER) istatistiksel olarak anlamlı pozitif ortalama getiriye sahiptir.

Payların çarşamba ve perşembe günleri ortalama getirileri istatistiksel olarak anlamlı bir şekilde sıfırdan farklı değildir. Cuma günü ise, yirmi beș pay pozitif ortalama getiri sağlamaktadır. Bu paylardan sadece on üçünün (BIMAS, DOHOL, ENKAI, EREGL, FROTO, KCHOL, OTKAR, PETKM, TAVHL, TCELL, TOASO, TUPRS ve YKBNK) getirisi istatistiksel olarak sifirdan farklıdır. Tablo 3'de yer alan ortalama getirileri genel olarak değerlendirildiğinde, çoğunun sıfıra yakın olduğu görülmektedir. 
Tablo 3. Payların Haftanın Günlerine İlişkin Tanımlayıcı İstatistikleri (\%)

\begin{tabular}{|c|c|c|c|c|c|c|c|c|c|c|}
\hline \multirow{2}{*}{ Pay Kodu } & \multicolumn{2}{|c|}{ Pazartesi } & \multicolumn{2}{|c|}{ Salı } & \multicolumn{2}{|c|}{ Çarşamba } & \multicolumn{2}{|c|}{ Perşembe } & \multicolumn{2}{|c|}{ Cuma } \\
\hline & Ort. & Std. & Ort. & Std. & Ort. & Std. & Ort. & Std. & Ort. & Std. \\
\hline AKBNK & 0,04 & 2,87 & 0,07 & 2,44 & 0,07 & 2,60 & 0,18 & 2,79 & $-0,01$ & 2,67 \\
\hline ARCLK & 0,17 & 2,88 & 0,00 & 2,54 & 0,07 & 2,30 & $-0,07$ & 2,49 & 0,13 & 2,33 \\
\hline BIMAS & 0,08 & 2,56 & 0,07 & 2,16 & 0,00 & 2,22 & 0,15 & 2,40 & $0,34^{* * *}$ & 2,65 \\
\hline DOHOL & $-0,05$ & 3,05 & $-0,04$ & 2,82 & 0,02 & 2,64 & 0,01 & 3,04 & $0,19^{*}$ & 2,69 \\
\hline EKGYO & $0,29^{* *}$ & 2,09 & 0,04 & 2,21 & $-0,15$ & 2,16 & 0,03 & 2,40 & 0,06 & 1,85 \\
\hline ENKAI & 0,09 & 2,35 & 0,03 & 2,26 & $-0,03$ & 2,16 & $-0,02$ & 2,24 & $0,33^{* * *}$ & 2,43 \\
\hline EREGL & 0,16 & 2,71 & $0,19^{* *}$ & 2,31 & $-0,04$ & 2,37 & 0,05 & 2,39 & $0,20^{* *}$ & 2,30 \\
\hline FROTO & 0,11 & 2,73 & $0,19^{*}$ & 2,58 & 0,05 & 2,18 & 0,04 & 2,58 & $0,19^{* *}$ & 2,36 \\
\hline GARAN & 0,04 & 2,91 & 0,13 & 2,62 & 0,08 & 2,72 & 0,13 & 2,90 & 0,11 & 2,60 \\
\hline HALKB & 0,18 & 2,80 & 0,03 & 2,69 & 0,11 & 2,60 & $-0,12$ & 2,97 & $-0,05$ & 2,73 \\
\hline ISCTR & 0,05 & 2,96 & 0,07 & 2,57 & 0.10 & 2,46 & 0,09 & 2,70 & 0,05 & 2,47 \\
\hline KCHOL & 0,09 & 2,73 & 0,07 & 2,27 & $-0,03$ & 2,18 & 0,01 & 2,42 & $0,20^{* *}$ & 2,27 \\
\hline KOZAL & 0,21 & 2,84 & 0,06 & 2,72 & 0,18 & 2,54 & $-0,13$ & 2,73 & 0,00 & 2,63 \\
\hline KRDMD & 0,18 & 3,58 & 0,07 & 3,17 & 0,10 & 3,06 & 0,17 & 3,01 & 0,15 & 3,01 \\
\hline MGROS & 0,02 & 2,61 & 0,08 & 2,34 & 0,14 & 2,42 & 0,02 & 2,59 & 0,11 & 2,27 \\
\hline OTKAR & 0,06 & 2,91 & 0,10 & 2,60 & 0,08 & 2,36 & 0,12 & 2,30 & $0,29^{* * *}$ & 2,55 \\
\hline PETKM & 0,07 & 2,69 & $-0,05$ & 2,36 & $-0,08$ & 2,05 & 0,10 & 2,39 & $0,16^{*}$ & 2,34 \\
\hline PGSUS & $0,51^{* *}$ & 2,61 & 0,18 & 3,04 & $-0,21$ & 2,66 & $-0,07$ & 2,67 & $-0,11$ & 2,67 \\
\hline SAHOL & 0,04 & 2,72 & 0,02 & 2,37 & $-0,03$ & 2,36 & 0,15 & 2,67 & 0,13 & 2,38 \\
\hline SISE & 0,13 & 2,58 & 0,07 & 2,29 & 0,00 & 2,23 & 0,11 & 2,44 & 0,12 & 2,36 \\
\hline TAVHL & 0,17 & 2,85 & $-0,05$ & 2,34 & 0,10 & 2,60 & $-0,20$ & 2,56 & $0,23^{*}$ & 2,66 \\
\hline TCELL & $-0,07$ & 2,50 & 0,01 & 2,12 & $-0,01$ & 2,21 & 0,07 & 2,49 & $0,33^{* *}$ & 2,24 \\
\hline THYAO & $0,20^{*}$ & 2,70 & 0,15 & 2,58 & 0,04 & 2,43 & 0,00 & 2,55 & 0,02 & 2,28 \\
\hline TKFEN & 0,04 & 2,87 & 0,07 & 2,49 & 0,04 & 2,19 & 0,03 & 2,46 & $-0,16$ & 2,60 \\
\hline TOASO & 0,15 & 3,14 & 0,14 & 2,64 & $-0,04$ & 2,51 & 0,06 & 2,76 & $0,21^{* *}$ & 2,63 \\
\hline TTKOM & 0,10 & 1,87 & $-0,03$ & 1,87 & 0,05 & 1,68 & 0,02 & 1,98 & 0,12 & 1,92 \\
\hline TUPRS & 0,11 & 2,44 & 0,07 & 2,36 & 0,04 & 2,29 & 0,06 & 2,35 & $0,24^{* *}$ & 2,35 \\
\hline ULKER & $0,20^{*}$ & 2,88 & $0,28^{* *}$ & 2,81 & $-0,06$ & 2,34 & 0,09 & 2,50 & 0,13 & 2,40 \\
\hline VAKBN & 0,15 & 2,78 & 0,02 & 2,61 & 0,01 & 2,75 & $-0,04$ & 2,77 & $-0,01$ & 2,53 \\
\hline YKBNK & $-0,05$ & 2,96 & 0,04 & 2,59 & 0,03 & 2,59 & 0,09 & 2,78 & $0,23^{* *}$ & 2,59 \\
\hline
\end{tabular}

Ortalama getiri ve bunlar ile ilgili standart sapma değerleri yüzde şeklinde ifade edilmektedir. ${ }^{* * *},{ }^{* *}$, ortalama getirilerin t-testine göre istatistiksel olarak anlamlı bir şekilde sırasıyla \%1, \%5 ve \%10 düzeyinde sıfırdan farklı olduğunu göstermektedir. Paylar için analiz edilen gün sayısı ve analize başlangıç tarihleri Tablo 2'de açıklandığı gibidir. 
Tablo 4, payların haftanın günlerine ilişkin getiri serilerinin Kolmogorov-Smirnov normallik testi sonuçları göstermektedir. Birçok getiri serisi için normal dağılımın varlığını iddia eden sıfır hipotezi \%1 anlamlılık düzeyinde reddedilmektedir. Bu nedenle çalışmada, payların hafta içi günlerde sağladığı ortalama getiriler arasında farklılık olup olmadığı parametrik olmayan testler yardımıyla araştırılmaktadır.

Tablo 4. Kolmogorov-Smirnov Normallik Testi Sonuçları

\begin{tabular}{|c|c|c|c|c|c|}
\hline Pay Kodu & Pazartesi & Salı & Çarşamba & Perşembe & Cuma \\
\hline AKBNK & $0,059^{* * *}$ & $0,059^{* * *}$ & $0,050^{* * *}$ & $0,050^{* * * x}$ & $0,061^{* * x+1}$ \\
\hline ARCLK & $0,099^{* * *}$ & $0,066^{* * *}$ & $0,059^{* * *}$ & $0,059^{* * *}$ & $0,060^{* * x}$ \\
\hline BIMAS & $0,095^{* * *}$ & $0,077^{* * *}$ & $0,070^{* * *}$ & $0,111^{* * *}$ & $0,099^{* * *}$ \\
\hline DOHOL & $0,115^{* * *}$ & $0,107^{* * *}$ & $0,121^{* * *}$ & $0,109^{* * * x}$ & $0,107^{*+\times x}$ \\
\hline EKGYO & $0,102^{* * *}$ & $0,065^{* *}$ & $0,064^{* *}$ & $0,073^{* * *}$ & $0,061^{* *}$ \\
\hline ENKAI & $0,072^{* * *}$ & $0,083^{* * *}$ & $0,071^{* * *}$ & $0,057^{* * *}$ & $0,072^{*+*}$ \\
\hline EREGL & $0,076^{* * *}$ & $0,057^{* * *}$ & $0,062^{* * *}$ & $0,082^{* * *}$ & $0,071^{* * x}$ \\
\hline FROTO & $0,092^{* * *}$ & $0,088^{* * *}$ & $0,064^{* * *}$ & $0,082^{* * *}$ & $0,075^{* * x}$ \\
\hline GARAN & $0,072^{* * *}$ & $0,057^{* * *}$ & $0,050^{* * *}$ & $0,048^{* * *}$ & $0,053^{*+x}$ \\
\hline HALKB & $0,073^{* * *}$ & $0,073^{* * *}$ & $0,062^{* * *}$ & $0,060^{* * *}$ & $0,056^{*+*+}$ \\
\hline ISCTR & $0,076^{* * *}$ & $0,050^{* * * *}$ & $0,062^{* * *}$ & $0,052^{* * *}$ & $0,057^{x+x+1}$ \\
\hline KCHOL & $0,068^{* * *}$ & $0,070^{* * *}$ & $0,065^{* * *}$ & $0,058^{*+*}$ & $0,070^{* * x}$ \\
\hline KOZAL & $0,064^{* * *}$ & $0,056^{* *}$ & $0,068^{* * *}$ & $0,067^{* * *}$ & $0,084^{* * x+}$ \\
\hline KRDMD & $0,113^{* x+x}$ & $0,138^{* * *}$ & $0,116^{* * *}$ & $0,099^{* * *}$ & $0,128^{x+x}$ \\
\hline MGROS & $0,090^{* * *}$ & $0,116^{* * *}$ & $0,099^{* * *}$ & $0,086^{* * *}$ & $0,085^{* * *}$ \\
\hline OTKAR & $0,096^{* * *}$ & $0,094^{* * *}$ & $0,077^{* * *}$ & $0,095^{* * *}$ & $0,093^{* * x}$ \\
\hline PETKM & $0,102^{* * *}$ & $0,078^{* * *}$ & $0,076^{* * *}$ & $0,086^{* * *}$ & $0,109^{x+x}$ \\
\hline PGSUS & $0,089^{* *}$ & 0,068 & $0,105^{* * *}$ & 0,068 & $0,091^{* *}$ \\
\hline SAHOL & $0,076^{* * *}$ & $0,072^{* * *}$ & $0,052^{* * *}$ & $0,054^{* * *}$ & $0,053^{x+x}$ \\
\hline SISE & $0,068^{* * *}$ & $0,050^{* * *}$ & $0,064^{* * *}$ & $0,049^{* * *}$ & $0,082^{* * x}$ \\
\hline TAVHL & $0,077^{* * *}$ & $0,065^{* * *}$ & $0,095^{* * *}$ & $0,093^{* * *}$ & $0,103^{x+x}$ \\
\hline TCELL & $0,082^{* * *}$ & $0,089^{* * *}$ & $0,074^{* * *}$ & $0,067^{* * *}$ & $0,071^{*+* x}$ \\
\hline THYAO & $0,069^{* * * *}$ & $0,065^{* * *}$ & $0,068^{* * *}$ & $0,054^{* * *}$ & $0,071^{* * x}$ \\
\hline TKFEN & $0,107^{* * *}$ & $0,070^{* * *}$ & $0,054^{* * *}$ & $0,068^{* * *}$ & $0,129^{x+x}$ \\
\hline TOASO & $0,081^{* * *}$ & $0,062^{* * *}$ & $0,062^{* * *}$ & $0,063^{* * *}$ & $0,073^{* * x}$ \\
\hline ТTКОМ & $0,062^{* * *}$ & $0,079^{* * *}$ & $0,053^{* *}$ & $0,060^{* * *}$ & $0,075^{* * * x}$ \\
\hline TUPRS & $0,076^{* * *}$ & $0,073^{* * *}$ & $0,066^{* * *}$ & $0,072^{* * *}$ & $0,092^{x+x+1}$ \\
\hline ULKER & $0,100^{* * *}$ & $0,114^{* * *}$ & $0,097^{* * *}$ & $0,081^{* * *}$ & $0,110^{* * x}$ \\
\hline VAKBN & $0,076^{* * *}$ & $0,048^{* * *}$ & $0,048^{* * *}$ & $0,039^{*}$ & $0,064^{* * x+}$ \\
\hline YKBNK & $0,074^{* * *}$ & $0,044^{* * *}$ & $0,047^{* * *}$ & $0,062^{* * *}$ & $0,083^{* * \times}$ \\
\hline
\end{tabular}

***, ${ }^{* *},{ }^{*}$ sırasıyla \%1, \%5 ve \%10 düzeyinde anlamlılığ göstermektedir. Paylar için analiz edilen gün sayısı ve analize başlangıç tarihleri Tablo 2'de açıklandığı gibidir. 
Tablo 5, parametrik olmayan istatistiksel analiz yöntemlerinden olan Kruskal-Wallis testi sonuçlarını göstermektedir. Ki-kare değerleri, BIMAS, EKGYO ve TCELL dışında tüm paylar için istatistiksel olarak anlamsızdır. Ki-kare değeri, BIMAS ve EKGYO için \%10 düzeyinde TCELL içinse, \%5 düzeyinde istatistiksel olarak anlamlıdır. Bundan dolayı, bu üç payın hafta içi günlerde sağladığı ortalama getiriler arasında farklılık olmadığını ileri süren $\mathrm{H}_{0}$ hipotezi reddedilmekte ve hafta içi günlerde farklı ortalama getiriler sağladıkları ortaya koyulmaktadır. Bir başka ifadeyle, BIMAS, EKGYO ve TCELL payları için haftanın günü etkisinin varlığı kanıtlanmaktadır. Bu bulgu, BIST 30 endeksinde üç pay dışında kalan diğer 27 payın fiyat hareketlerinin geçmiş fiyat verileri kullanılarak tahmin edilemeyeceğini göstermektedir.

Tablo 5. Kruskal-Wallis Testi Sonuçları

\begin{tabular}{|c|c|c|c|}
\hline Pay Kodu & Ki-Kare Değeri & p-değeri & $\mathrm{H}_{0}$ Hipotezi \\
\hline AKBNK & 2,255 & 0,689 & Kabul \\
\hline ARCLK & 2,553 & 0,635 & Kabul \\
\hline BIMAS & $8,059^{*}$ & 0,089 & Ret \\
\hline DOHOL & 2,979 & 0,561 & Kabul \\
\hline EKGYO & $8,358^{*}$ & 0,079 & Ret \\
\hline ENKAI & 6,999 & 0,136 & Kabul \\
\hline EREGL & 3,962 & 0,411 & Kabul \\
\hline FROTO & 1,502 & 0,826 & Kabul \\
\hline GARAN & 0,335 & 0,987 & Kabul \\
\hline HALKB & 3,846 & 0,427 & Kabul \\
\hline ISCTR & 0,453 & 0,978 & Kabul \\
\hline KCHOL & 4,629 & 0,328 & Kabul \\
\hline KOZAL & 2,313 & 0,678 & Kabul \\
\hline KRDMD & 2,835 & 0,586 & Kabul \\
\hline MGROS & 2,279 & 0,685 & Kabul \\
\hline OTKAR & 2,432 & 0,657 & Kabul \\
\hline PETKM & 3,707 & 0,447 & Kabul \\
\hline PGSUS & 4,945 & 0,293 & Kabul \\
\hline SAHOL & 2,784 & 0,595 & Kabul \\
\hline SISE & 2,322 & 0,677 & Kabul \\
\hline TAVHL & 7,037 & 0,134 & Kabul \\
\hline TCELL & $12,545^{* *}$ & 0,014 & Ret \\
\hline THYAO & 3,275 & 0,513 & Kabul \\
\hline TKFEN & 2,852 & 0,583 & Kabul \\
\hline TOASO & 2,416 & 0,660 & Kabul \\
\hline TTKOM & 1,078 & 0,898 & Kabul \\
\hline TUPRS & 1,647 & 0,800 & Kabul \\
\hline ULKER & 4,273 & 0,370 & Kabul \\
\hline VAKBN & 3,588 & 0,465 & Kabul \\
\hline YKBNK & 2,756 & 0,599 & Kabul \\
\hline \multicolumn{4}{|c|}{$\begin{array}{l}\mathrm{H}_{0} \text { hipotezi, payların hafta içi günlerde sağladığı ortalama getiriler arasında farklılık } \\
\text { olmadığını ileri sürmektedir. Bu hipotezin kabul edilmesi haftanın günü etkisinin yokluğunu; } \\
\text { reddedilmesi ise, haftanın günü etkisinin varlığını ifade etmektedir. }{ }^{* *} \text { * }{ }^{*} \text { sirasılla } \% 5 \text { ve } \% 10 \\
\text { düzeyinde anlamlılığı göstermektedir. Paylar için analiz edilen gün sayısı ve analize başlangı̧ } \\
\text { tarihleri Tablo 2'de açıklandığı gibidir. }\end{array}$} \\
\hline
\end{tabular}


Ortalama getirilerin eşitliğini ileri süren $\mathrm{H}_{0}$ hipotezinin reddedilmesine neden olan hafta içi günlerin belirlenebilmesi için Wilcoxon sıralama toplamı testi uygulanmaktadır. Bu test, haftanın iki gününe ilişkin getirilerin birbirinden anlamlı bir şekilde farklılık gösterip göstermediğini tespit etmektedir. Kruskal-Wallis testi sonuçlarına göre sadece BIMAS, EKGYO ve TCELL paylarında haftanın günü etkisine dair bulgular elde edildiği için test, sadece bu üç pay için gerçekleştirilmektedir. Wilcoxon sıralama toplamı testi Z istatistiği değerleri, Tablo 6 'da sunulmaktadır. BIMAS ve TCELL'nin cuma günü ortalama getirisi pazartesi, salı ve çarşamba günlerinden istatistiksel olarak anlamlı bir şekilde farklıdır. Bu durum BIMAS ve TCELL'nin cuma günü, pazartesi, salı ve çarşamba günü getirilerine göre anlamlı bir şekilde daha yüksek getirilere sahip olduklarını işaret etmektedir. EKGYO içinse pazartesi, en yüksek getiriye sahip gündür ve bu getiri istatistiksel olarak anlamlı bir şekilde diğer hafta içi günlerin getirilerinden farklıdir.

Tablo 6. Wilcoxon Sıralama Toplamı Testi Sonuçları

\begin{tabular}{lccc}
\hline & BIMAS & EKGYO & TCELL \\
\hline Pazartesi - Salı & $-0,439$ & $-1,671^{*}$ & $-0,328$ \\
Pazartesi - Çarşamba & $-0,695$ & $-2,785^{* * *}$ & $-0,177$ \\
Pazartesi - Perşembe & $-0,931$ & $-1,634^{*}$ & $-1,079$ \\
Pazartesi - Cuma & $-1,638^{*}$ & $-2,079^{* *}$ & $-2,647^{* * *}$ \\
Salı - Çarşamba & $-0,317$ & $-1,071$ & $-0,112$ \\
Salı - Perşembe & $-1,495$ & $-0,012$ & $-1,360$ \\
Salı - Cuma & $-2,142^{* *}$ & $-0,166$ & $-3,012^{* * *}$ \\
Çarşamba - Perşembe & $-1,708^{*}$ & $-1,060$ & $-1,224$ \\
Çarşamba - Cuma & $-2,356^{* *}$ & $-1,008$ & $-2,874^{* * *}$ \\
Perşembe - Cuma & $-0,725$ & $-0,174$ & $-1,535$ \\
\hline
\end{tabular}

****** * sırasılyla \%1, \%5 ve \%10 düzeyinde anlamlılı̆̆ı göstermektedir. Paylar için analiz edilen gün sayısı ve analize başlangıç tarihleri Tablo 2'de açıklandığı gibidir.

\section{Sonuç}

Payların hafta içi günlerde farklı ortalama getiriler sağlayıp sağlamadığı birçok araştırmaya konu olmuştur. Bu konuyla ilgili literatür incelendiğinde, payların en düşük ortalama getiriyi pazartesi günüleri; en yüksek ortalama getiriyi ise, cuma günleri sağladığı ileri sürülmektedir. Bu durum, haftanın günü anomalisi ya da haftanın günü etkisi (the day of the week effect) olarak bilinmektedir. Bu çalışmada, 20 Ağustos 2015 tarihi itibariyle BIST 30 endeksinde yer alan otuz 
payın 02 Ocak 2003 - 29 Mayıs 2015 tarihleri arasındaki verilerini kullanılarak, bu paylar için haftanın günü etkisi araştırılmaktadır. Çalışmada, verilerin normal dağılıma uymaması nedeniyle haftanın günü etkisini araştırmak için parametrik olamayan istatistiksel analiz yöntemlerinden olan Kruskal-Wallis ve Wilcoxon sıralama toplamı testleri kullanılmaktadır.

BIST 30 endeksinde yer alan paylardan dördünün pazartesi (EKGYO, PGSUS, THYAO ve ULKER), üçünün salı (EREGL, FROTO ve ULKER) ve on üçünün de cuma günü (BIMAS, DOHOL, ENKAI, EREGL, FROTO, KCHOL, OTKAR, PETKM, TAVHL, TCELL, TOASO, TUPRS ve YKBNK) istatistiksel olarak anlamlı pozitif ortalama getiri sağladığı görülmektedir. Ancak literatürün aksine, hiçbir payın pazartesi ya da salı günü istatistiksel olarak anlamlı negatif ortalama getiri sağladığı bulunamamıştır. Payların hafta içi günlere ilişkin ortalama getirileri genel olarak incelendiğinde, birçoğu sıfıra yakındır.

Haftanın günü etkisinin varlığını ispat etmek için kullanılan Kruskal-Wallis testi sonuçları, BIMAS, EKGYO ve TCELL payları dışında kalan yirmi yedi pay için haftanın günü etkisinin varlığını ortaya koyamamaktadır. Bu test sonrasında BIMAS, EKGYO ve TCELL payları için uygulanan Wilcoxon sıralama toplamı testi sonuçları ise, BIMAS ve TCELL'nin cuma günü ortalama getirisinin haftanın diğer üç gününden (pazartesi, salı ve çarşamba); EKGYO’nun pazartesi ortalama getirisinin ise, haftanın diğer tüm günlerinden (salı, çarşamba, perşembe ve cuma) farklı olduğunu göstermektedir. Tüm bu sonuçlar, incelenen dönemde piyasa değeri büyük paylar için haftanın günü etkisinin azaldığı anlamına gelmektedir.

Bundan sonra yapılacak çalışmalarda piyasa değeri küçük paylar da analiz kapsamına alınarak, bu paylarda haftanın günü etkisi araştırılabilir. Çalışmada sunulan sonuçların geçerliliği, farklı metodolojiler kullanılarak karşılaştırılabilir. Ayrıca incelenen dönem, 2008 küresel ekonomik krizi dikkate alınarak alt dönemlere bölünüp krizin haftanın günü anomalisi üzerindeki etkisi incelenebilir. 


\section{Kaynaklar}

ABDIOĞLU, Zehra ve DEĞIRMENCI, Nurdan. (2013). İstanbul Menkul Kiymetler Borsasında Mevsimsel Anomaliler. Business and Economics Research Journal, 4(3): 55-73.

AJAYI, Richard A., MEHDIAN, Seyed ve PERRY, Mark J. (2004). The Day-of-the-Week Effect in Stock Returns : Further Evidence from Eastern European Emerging Markets. Emerging Markets Finance and Trade, 40(4): 53-62.

AKSOY, Mine. (2013). Day of the Week Anomaly for Istanbul Gold Exchange: Gold and Silver Data. Muhasebe ve Finans Dergisi(57): 149-164.

AKTAŞ, Hüseyin ve KOZANOĞLU, Metin. (2007). Haftanın Günleri Etkisini İstanbul Menkul Kıymetler Borsası'nda GARCH Modeli ile Test Edilmesi. Finansal Politik \& Ekonomik Yorumlar Dergisi, 44(514): 37-45.

ATAKAN, Tülin. (2008). İstanbul Menkul Kıymetler Borsası'nda Haftanın Günü Etkisi ve Ocak Ayı Anomalilerinin ARCH-GARCH Modelleri ile Test Edilmesi. İstanbul Üniversitesi İşletme Fakültesi Dergisi, 37(2): 98-110.

AYDOĞAN, Kürşat ve BOOTH, G. Geoffrey. (2003). Calendar Anomalies in the Turkish Foreign Exchange Markets. Applied Financial Economics, 13(5): 353-360.

BALABAN, Ercan. (1995). Day of the Week Effects: New Evidence from an Emerging Stock Market. Applied Economics Letters, 2(5): 139-143.

BASHER, Syed A. ve SADORSKY, Perry. (2006). Day-of-the-Week Effects in Emerging Stock Markets. Applied Economics Letters, 13(10): 621-628.

BAŞDAŞ, Ülkem. (2011). The Day-of-the-Week Effect for Istanbul Stock Exchange: A Stochastic Dominance Approach. Journal of Applied Finance \& Banking, 1(4): 223-238.

BILDIK, Recep. (2000). Hisse Senedi Piyasalarında Dönemsellikler ve İMKB Üzerine Ampirik Bir Çalışma. İMKB.

BROOKS, Chris ve PERSAND, Gita. (2001). Seasonality in Southeast Asian Stock Markets: Some New Evidence on Day-of-the-Week Effects. Applied Economics Letters, 8(3): 155-158.

BÜYÜKŞALVARCI, Ahmet. (2010). Ekonomik Krizler ve İMKB’nda Haftanın Günü Etkisi. Journal of Accounting \& Finance(45): 108-126.

CHANG, Eric C., PINEGAR, J. Michael ve RAVICHANDRAN, Ravi. (1993). International Evidence on the Robustness of the Day-of-the-Week Effect. The Journal of Financial and Quantitative Analysis, 28(4): 497-513.

CHOUDHRY, Taufiq. (2000). Day of the Week Effect in Emerging Asian Stock Markets: Evidence from the GARCH Model. Applied Financial Economics, 10(3): 235-242.

CONDOYANNI, L., O’HANLON, J. ve WARD, C. W. R. (1987). Day of the Week Effects on Stock Returns: International Evidence. Journal of Business Finance \& Accounting, 14(2): 159-174.

CONNOLLY, Robert A. (1989). An Examination of the Robustness of the Weekend Effect. Journal of Financial and Quantitative Analysis, 24(02): 133-169.

CONNOLLY, Robert A. (1991). A Posterior Odds Analysis of the Weekend Effect. Journal of Econometrics, 49(1-2): 51-104.

CROSS, Frank. (1973). The Behavior of Stock Prices on Fridays and Mondays. Financial Analysts Journal, 29(6): 67-69.

ÇIÇEK, Macide. (2008). Türkiye'de Devlet İç Borçlanma Senetlerinin Günlük Getirilerinde Mevsimsellik ve Koşullu Risk. İktisat İşletme ve Finans, 23(264): 93-118. 
ÇIÇEK, Macide. (2013). The Day-of-the-Week Effect on Return and Volatility in the Turkish Stock Markets. Journal of Applied Finance \& Banking, 3(4): 143-167.

DEMIRER, Riza ve KARAN, Mehmet B. (2002). An Investigation of the Day-of-the-Week Effect on Stock Returns in Turkey. Emerging Markets Finance \& Trade: 47-77.

DICLE, Mehmet F. ve HASSAN, M. Kabir. (2007). Day of the Week Effect in Istanbul Stock Exchange. Scientific Journal of Administrative Development, 5.

DICLE, Mehmet F. ve LEVENDIS, John D. (2014). The Day-of-the-Week Effect Revisited: International Evidence. Journal of Economics and Finance, 38(3): 407-437.

DUBOIS, M. ve LOUVET, P. (1996). The Day-of-the-Week Effect: The International Evidence. Journal of Banking \& Finance, 20(9): 1463-1484.

EASTON, Stephen A. ve FAFF, Robert W. (1994). An Investigation of the Robustness of the Day-of-theWeek Effect in Australia. Applied Financial Economics, 4(2): 99-110.

EKEN, Mehmet H. ve UNER, Taylan O. (2010). Calendar Effects in the Stock Market and a Practice Relatedn to the Istanbul Stock Exchange Market (ISEM). Istanbul Stock Exchange Review, 12(45): 59-95.

ERGÜL, Nuray, AKEL, Veli ve DUMANOĞLU, Sezai. (2009). Sektör Endekslerinde Haftanını Günü Etkisinin Araştırılması. World of Accounting Science, 11(2).

ERGÜL, Nuray, DUMANOĞLU, Sezai ve AKEL, Veli. (2008). İMKB'de Günlük Anomaliler. Marmara Üniversitesi I.I.I.B.F. Dergisi, 25(2): 601-629.

FAMA, Eugene F. (1965). The Behavior of Stock-Market Prices. The Journal of Business, 38(1): 34-105.

FAMA, Eugene F. (1970). Efficient Capital Markets: A Review of Theory and Empirical Work. The Journal of Finance, 25(2): 383-417.

FRENCH, Kenneth R. (1980). Stock Returns and the Weekend Effect. Journal of Financial Economics, 8(1): 55-69.

GIBBONS, Michael R. ve HESS, Patrick. (1981). Day of the Week Effects and Asset Returns. The Journal of Business, 54(4): 579-596.

GREGORIOU, A., KONTONIKAS, A. ve TSITSIANIS, N. (2004). Does the Day of the Week Effect Exist Once Transaction Costs Have Been Accounted For? Evidence from the UK. Applied Financial Economics, 14(3): 215-220.

GÜNEYSU, Filiz ve YAMAK, Nebiye. (2011). İMKB'de Haftanın Günü Etkisinin Kriz Dönemleri için Araştırılması. Finans Politik \& Ekonomik Yorumlar, 48(560): 33-44.

HAMARAT, Bahattin ve TUFAN, Ekrem. (2008). Is the Turkish Tourism Sector Index Efficient? Anadolu Üniversitesi Sosyal Bilimler Dergisi, 8(2): 169-184.

HUI, Tak-Kee. (2005). Day-of-the-Week Effects in US and Asia-Pacific Stock Markets During the Asian Financial Crisis: A Non-Parametric Approach. Omega, 33(3): 277-282.

İNAMLIK, Ali, BERUMENT, Hakan ve KIYMAZ, Halil. (2004). Borsa Değişkenliğinde Haftanın Gün Etkisi: İMKB. İktisat İşletme ve Finans, 19(223): 91-102.

JAFFE, Jeffrey ve WESTERFIELD, Randolph. (1985). The Week-End Effect in Common Stock Returns: The International Evidence. The Journal of Finance, 40(2): 433-454.

KALAYCI, Şeref. (2010). SPSS Uygulamalı Çok Değişkenli Istatistik Teknikleri. (5. Baskı). Ankara: Asil Yayın Dağıtım.

KAMATH, Ravindra ve CHUSANACHOTI, Jirayuth. (2002). An Investigation of the Day-of-the-Week Effect in Korea: Has the Anomalous Effect Vanished in the 1990s. International Journal of Business, 7(1): 47-62.

KARAN, Mehmet B. (2002). İstanbul Menkul Kıymetler Borsası Sektör Endekslerinde Haftanın Günleri ve 
Ocak Ayı Etkilerinin Test Edilmesi. İktisat İşletme ve Finans, 17(190): 51-59.

KARAN, Mehmet B. ve UYGUR, Akyay. (2001). İstanbul Menkul Kıymetler Borsası'nda Haftanın Günleri ve Ocak Ayı Etkilerinin Firma Büyüklüğü Açısından Değerlendirilmesi. Ankara Üniversitesi SBF Dergisi, 56(2): 103-115.

KAYALIDERE, Koray ve AKTAŞ, Hüseyin. (2012). Vadeli İşlem Ve Opsiyon Borsasında Risk-Getiri Etkileşimi ve Haftanın Günleri Etkisinin İncelenmesi. Süleyman Demirel Üniversitesi İktisadi ve İdari Bilimler Fakültesi Dergisi, 17(3): 321-338.

KEIM, Donald B. ve STAMBAUGH, Robert F. (1984). A Further Investigation of the Weekend Effect in Stock Returns. The Journal of Finance, 39(3): 819-835.

KIYILAR, Murat ve KARAKAŞ, Cem. (2005). İstabul Menkul Kiymetler Borsası’nda Zaman Dayalı Anomalilere Yönelik Bir İnceleme. Yönetim(52): 17-25.

KOHERS, G., KOHERS, N., PANDEY, V. ve KOHERS, T. (2004). The Disappearing Day-of-the-Week Effect in the World's Largest Equity Markets. Applied Economics Letters, 11(3): 167-171.

KONAK, Fatih ve KENDIRLI, Selçuk. (2014). Küresel Finansal Kriz Sürecinde BIST 100 Endeksi’nde Haftanın Günleri Etkisinin Analizi. Süleyman Demirel Üniversitesi İktisadi ve İdari Bilimler Fakültesi Dergisi, 19(2): 275-286.

KORKMAZ, Turhan, BAŞARAN, Ümit ve ÇEVIK, Emrah İ. (2010). Yaz Saati Uygulaması Anomalisinin İMKB 100 Endeks Getirisine Etkisinin Test Edilmesi. Ege Akademik Bakış, 10(4): 1139-1153.

LIM, Shion Y. ve CHIA, Ricky C.-J. (2010). Stock Market Calendar Anomalies: Evidence from Asean - 5 Stock Markets. Economics Bulletin, 30(2): 996-1005.

LIU, Benjamin ve LI, Bin. (2010). Day-of-the-Week Effects: Another Evidence from Top 50 Australian Stocks. European Journal of Economics, Finance and Administrative Sciences (24): 78-87.

MURADOĞLU, Gülnur ve OKTAY, Türkay. (1993). Hisse Senedi Piyasasında Zayıf Etkinlik: Takvim Anomalileri. Hacettepe Üniversitesi İIBF Dergisi, 11: 51-62.

OĞUZSOY, Cemal B. ve GÜVEN, Sibel. (2003). Stock Returns and the Day-of-the-Week Effect in Istanbul Stock Exchange. Applied economics, 35(8): 959-971.

ÖZMEN, Tahsin. (1997). Dünya Borsalarında Gözlemlenen Anomaliler ve İstanbul Menkul Kıymetler Borsası Üzerine Bir Deneme. Ankara: Sermaye Piyasası Kurulu.

RUBINSTEIN, Mark. (2001). Rational Markets: Yes or No? The Affirmative Case. Financial Analysts Journal, 57(3): 15-29.

SAMUELSON, Paul A. (1965). Proof That Properly Anticipated Prices Fluctuate Randomly. Industrial Management Review, 6(2): 41-49.

SMIRLOCK, Michael ve STARKS, Laura. (1986). Day-of-the-Week and Intraday Effects in Stock Returns. Journal of Financial Economics, 17(1): 197-210.

SOLNIK, Bruno ve BOUSQUET, Laurance. (1990). Day-of-the-Week Effect on the Paris Bourse. Journal of Banking \& Finance, 14(2-3): 461-468.

STEELEY, James M. (2001). A Note on Information Seasonality and the Disappearance of the Weekend Effect in the UK Stock Market. Journal of Banking \& Finance, 25(10): 1941-1956.

SULLIVAN, Ryan, TIMMERMANN, Allan ve WHITE, Halbert. (2001). Dangers of Data Mining: The Case of Calendar Effects in Stock Returns. Journal of Econometrics, 105(1): 249-286.

TUNCEL, Ahmet K. (2008). Haftanın Günü Etkisi’ne Yeni Bir Yaklaşım: İMKB Örneği. Trakya Üniversitesi Sosyal Bilimler Dergisi, 10(2): 246-271.

TUNÇEL, Ahmet K. (2007). İMKB’de Haftanin Günü Etkisi. Akdeniz Üniversitesi Î́BF Dergisi, 13: 252-265. 